\title{
UAV-based Multispectral \& Thermal dataset for exploring the diurnal variability, radiometric \& geometric accuracy for precision agriculture
}

\author{
Christina Kallimani ${ }^{1}$, Ramin Heidarian Dehkordi², Frits K. van Evert ${ }^{3}$, Lammert Kooistra ${ }^{4}$, Bert Rijk ${ }^{1}$ \\ ${ }^{1}$ Aurea Imaging, Weg der Verenigde Naties 1, 3527 KT Utrecht, Netherlands \\ ${ }^{2}$ Department of Environmental Sciences and Management, University of Liege, Avenue de Longwy 185 , \\ B-6700 Arlon, Belgium \\ ${ }^{3}$ Agrosystems Research, Wageningen University \& Research, Droevendaalsesteeg 1, 6708 PB \\ Wageningen, the Netherlands, \\ ${ }^{4}$ Laboratory of Geo-Information Science and Remote Sensing, Wageningen University \& Research, \\ P.O. Box 47, 6700 AA Wageningen, the Netherlands \\ *email: christina@aureaimaging.com,
}

\begin{abstract}
To explore the diurnal variations, radiometric and geometric accuracy of UAV-based data for precision agriculture, a comprehensive dataset was created in a one-day field campaign (21 June 2017). The multi-sensor data set covers wheat, barley \& potato experimental fields, located in Wageningen University and Research (WUR) farm maintained by Unifarm. UAV-based images were collected with several sensors over the experimental area, starting from 7:25am and ending at 20:00pm local solar time. The dataset consists of images collected from 30 flights: 9 flights with senseFly multiSPEC 4C, 9 with Parrot Sequoia, 2 with Slant Range P3, 5 with DJI Zenmuse X3 NIR, 4 with the senseFly Thermo Map and 1 with the RGB Sony WX-220. Additionally, validation measurements at radiometric calibration plates and plant sample locations were taken with a Cropscan handheld spectrometer and a tec5 Handyspec spectrometer. The dataset consists of the validation measurements, the raw images and the processed orthomosaics (both with and without geometric correction).
\end{abstract}

Keywords: multispectral, thermal infrared, diurnal variability, unmanned aerial vehicles (UAV), precision agriculture, wheat, potato, barley.

1 INTRODUCTION: Multispectral and thermal sensors are becoming increasingly available for precision agriculture. Multiple studies refer to the capabilities of these sensors (Elarab et al. 2015; Gago et al. 2015; Haghighattalab et al. 2016; Holman et al. 2016; Potgieter et al. 2017; Raeva, Šedina, and Dlesk 2018; Sankaran et al. 2015; Shi et al. 2016; Zhang and Kovacs 2012). A few studies refer to the limitations and best practices, to achieve high-quality data (Aicardi et al. 2016; Assmann et al. 2018; Kelly et al. 2019; Maes, Huete, and Steppe 2017; Peña et al. 2015; Torres-Sánchez et al. 2013). However, in existing studies the emphasis is on the differences or complementary use of different sensors while the effect of the diurnal differences in the data is not fully explored. Moreover, there is a lack of freely available UAV-based datasets for testing the diurnal changes in real field conditions with multiple sensors. Therefore, the aim of this study is to explore daily variations in UAV-based data and the radiometric \& geometric accuracy of multiple sensors. During a field campaign on 21 June 2017 , three different crops were monitored: potato, wheat and barley. UAV-based images were collected from 7:25am up to 20:00pm local solar time. With the results from this dataset we aim to identify best practices for operational use, limitations and expectations based on time of flight and between sensors. The dataset is freely available for download, in different levels of processing. Level 0 contains the raw format (images in jpeg or tif format), level 1 contains the radiometrically corrected and stitched orthomosaic (in georeferenced tif format), and level 2 contains the geometrically corrected mosaic (in tif format).

\section{FIELD CAMPAIGN AND DATA COLLECTED:}

2.1 EXPERIMENTAL SITE: The fieldwork took place at the experimental fields of Unifarm (Figure 1), Wageningen University and Research (WUR), on the $21^{\text {st }}$ of June 2017 . The weather conditions during the flights were optimal, i.e. a cloudless sky and temperature variations from 19.5 to $25.2^{\circ} \mathrm{C}$ with a peak of $28.1^{\circ} \mathrm{C}$ at $15: 00 \mathrm{pm}$ according to data obtained from Royal Netherlands Meteorological Institute (KNMI) website (http://knmi.nl) (Figure 2). 


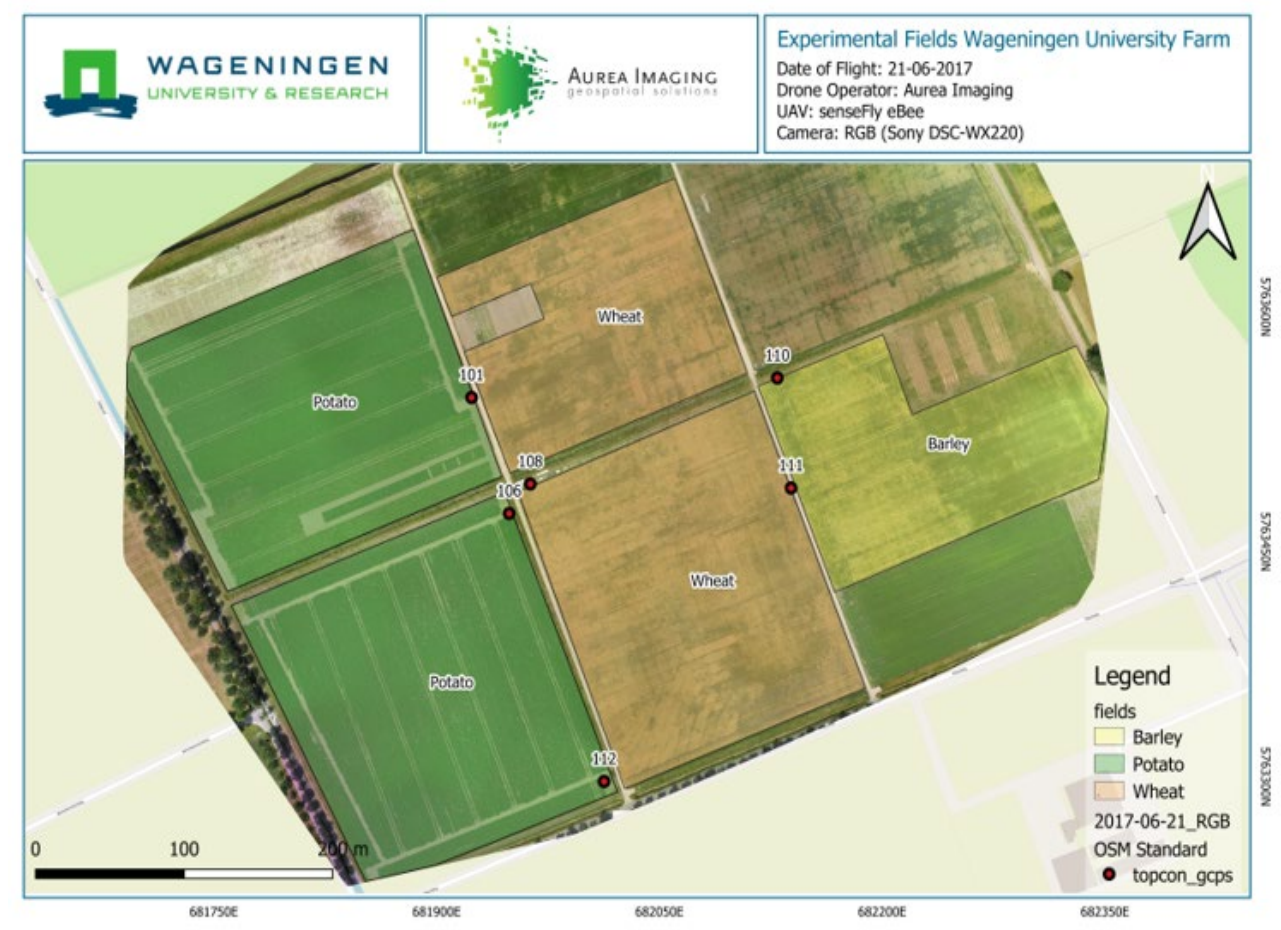

Figure 2. Location of Experimental Fields, and GCPs

TEMPERATURE ${ }^{\circ} \mathrm{C}$ FOR 21-06-2017

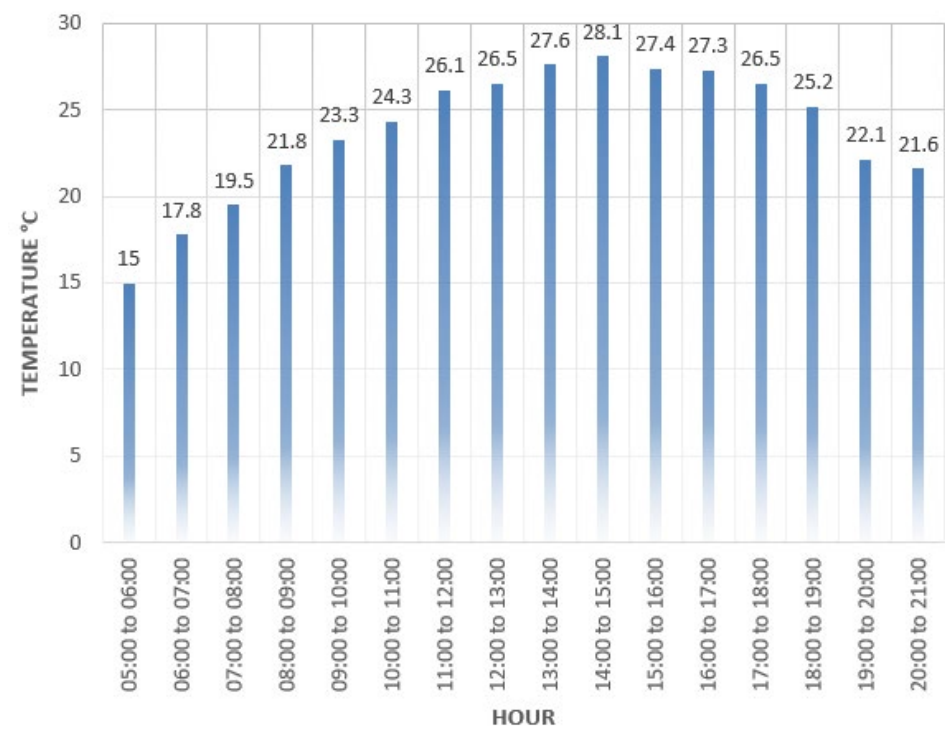

Figure 1. Hourly Temperature ${ }^{\circ} \mathrm{C}$ variation, source: $\mathrm{KNMI}$

2.2 FLIGHT PLANNING AND SENSORS: The flight planning: the sensors used, flight conditions and derived outputs are provided in Table 1. We aimed for a repetition of sensors at frequent intervals. The specifications of the sensors used during the fieldwork are presented in Table 2. 
Table 1. Flights Plan: sensors used, flight conditions and derived outputs

\begin{tabular}{|c|c|c|c|c|c|c|c|c|c|}
\hline Sensor & $\begin{array}{l}\text { Flight } \\
\text { ID }\end{array}$ & $\begin{array}{l}\text { Start } \\
\text { time }\end{array}$ & $\begin{array}{l}\text { Images } \\
\text { Collected }\end{array}$ & $\begin{array}{l}\text { Wind } \\
(\mathrm{m} / \mathrm{s})\end{array}$ & $\begin{array}{c}\text { Flight } \\
\text { Altitude } \\
\text { (m) }\end{array}$ & $\begin{array}{c}\text { Multi- } \\
\text { spectral }\end{array}$ & Thermal & $\begin{array}{c}\text { Modified } \\
\text { NDVI }\end{array}$ & RGB \\
\hline MSP4C & 1 & $7: 25$ & 496 & 5 & 115 & $\checkmark$ & & & \\
\hline Sequoia & 2 & $7: 42$ & 412 & 3.7 & 115 & $\checkmark$ & & & \\
\hline Sequoia & 3 & $7: 55$ & 596 & 4 & 115 & $\checkmark$ & & & \\
\hline MSP4C & 4 & $8: 14$ & 456 & 3 & 115 & $\checkmark$ & & & \\
\hline Thermo-map & 5 & $8: 29$ & 1606 & 3 & 105 & & $\checkmark$ & & \\
\hline MSP4C & 6 & $9: 10$ & 460 & 3.2 & 115 & $\checkmark$ & & & \\
\hline Sequoia & 7 & $9: 24$ & 592 & 3 & 115 & $\checkmark$ & & & \\
\hline Thermo-map & 8 & $9: 47$ & 1149 & 3.5 & 105 & & $\checkmark$ & & \\
\hline MSP4C & 9 & $10: 03$ & 448 & 3.6 & 115 & $\checkmark$ & & & \\
\hline Sequoia & 10 & $10: 22$ & 296 & 5.5 & 115 & $\checkmark$ & & & $\checkmark$ \\
\hline Slant Range & 11 & $10: 42$ & 2049 & 3.5 & 120 & $\checkmark$ & & & \\
\hline DJIX3 & 12 & $11: 06$ & 103 & 3 & 80 & & & $\checkmark$ & \\
\hline Thermo-map & 13 & $11: 48$ & 1157 & 3 & 105 & & $\checkmark$ & & \\
\hline MSP4C & 14 & $12: 02$ & 276 & 3 & 115 & $\checkmark$ & & & \\
\hline Sequoia & 15 & $12: 15$ & 312 & 4 & 115 & $\checkmark$ & & & $\checkmark$ \\
\hline DJIX3 & 17 & $13: 18$ & 123 & 2 & 80 & & & $\checkmark$ & \\
\hline Sequoia & 19 & $14: 40$ & 818 & 2.5 & 115 & $\checkmark$ & & & \\
\hline MSP4C & 20 & $14: 58$ & 352 & 3.4 & 115 & $\checkmark$ & & & \\
\hline DJIX3 & 21 & $15: 15$ & 103 & 3.4 & 80 & & & $\checkmark$ & \\
\hline RGB & 22 & $15: 40$ & 143 & 3.6 & 115 & & & & $\checkmark$ \\
\hline Slant Range & 23 & $16: 00$ & 2068 & 3.6 & 120 & $\checkmark$ & & & \\
\hline Sequoia & 24 & $16: 37$ & 792 & 2.4 & 115 & $\checkmark$ & & & \\
\hline MSP4C & 25 & $16: 56$ & 528 & 2.4 & 115 & $\checkmark$ & & & \\
\hline DJIX3 & 26 & $17: 10$ & 103 & 2.4 & 80 & & & $\checkmark$ & \\
\hline Thermo-map & 27 & $17: 38$ & 1611 & 2.7 & 105 & & $\checkmark$ & & \\
\hline MSP4C & 29 & 18:10 & 360 & 2.4 & 115 & $\checkmark$ & & & \\
\hline Sequoia & 30 & $18: 34$ & 572 & 2.4 & 115 & $\checkmark$ & & & \\
\hline MSP4C & 32 & 19:22 & 360 & 3.2 & 115 & $\checkmark$ & & & \\
\hline DJIX3 & 33 & 19:34 & 103 & 3.2 & 80 & & & $\checkmark$ & \\
\hline Sequoia & 34 & $19: 59$ & 432 & 3.2 & 115 & $\checkmark$ & & & \\
\hline
\end{tabular}

Table 2. Sensor characteristics

\begin{tabular}{|c|c|c|c|c|c|c|}
\hline Sensor type & UAV & Resolution & Bands & $\begin{array}{l}\text { Processing } \\
\text { Software }\end{array}$ & $\begin{array}{l}\text { Abbreviations } \\
\text { used in Table } 1\end{array}$ & Source \\
\hline $\begin{array}{c}\text { Multispectral, } \\
\text { Airinov multiSPEC } \\
4 \mathrm{C}\end{array}$ & eBee & $1.2 \mathrm{Mpx}$ & $\begin{array}{l}\text { Green, Red, Red } \\
\text { Edge, NIR }\end{array}$ & Pix4D & MSP4C & multiSPEC $4 \mathrm{C}$ \\
\hline $\begin{array}{c}\text { Multispectral, Parrot } \\
\text { Sequoia }\end{array}$ & eBee & $\begin{array}{c}1.2 \mathrm{Mpx} \text { (single } \\
\text { bands), } 16 \mathrm{Mpx} \text { (RGB) }\end{array}$ & $\begin{array}{l}\text { Green, Red, Red } \\
\text { Edge, NIR, RGB }\end{array}$ & Pix4D & Sequoia & $\underline{\text { Sequoia }}$ \\
\hline $\begin{array}{c}\text { Thermal, senseFly } \\
\text { ThermoMAP }\end{array}$ & eBee & $0.3 \mathrm{Mpx}$ & Thermal Infrared & Pix4D & Thermo-map & Thermo Map \\
\hline RGB, Sony WX-220 & eBee & 18.2 Mpx & Red, Green, Blue & Pix4D & RGB & dsc-wx220 \\
\hline $\begin{array}{l}\text { DJI, Zenmuse X3 } \\
\text { Blue-Green-NIR }\end{array}$ & DJIX3 & $12 \mathrm{Mpx}$ & Blue, Green, NIR & Pix4D & DJIX3 & zenmuse-x3 \\
\hline Slant Range, 3P & $\begin{array}{l}\text { DJI- } \\
\text { S950 }\end{array}$ & 1.3 Mpx & $\begin{array}{c}\text { Green, Red, Red } \\
\text { Edge, NIR }\end{array}$ & Pix4D & Slant Range & slantrange- $3 p$ \\
\hline
\end{tabular}

\subsection{RADIOMETRIC CALIBRATION MEASUREMENTS \& GROUND CONTROL POINTS (GCPS):}

For each multispectral flight, images of the sensor specific radiometric calibration target plates were taken before the flight. For the multiSPEC $4 \mathrm{C}$ and Sequoia sensors we used the Airinov and Parrot calibration targets. These targets are automatically detected and added to the processing workflow of the multispectral images (Figure 3). The ThermoMAP sensor performs an internal temperature 
calibration during the first minutes of the flight, after which it begins collecting images. The images for multispectral and thermal sensors were geo-tagged automatically with the onboard UAV flight controller's GPS device. For geo-tagging the RGB images of the Sony WX-220 sensor, the EXIF file from the UAV was imported in the e-Motion Flight Data Manager (www.sensefly.com) .

To co-register the entire dataset with high geometric accuracy we used 4 to 6 GCPs measured by an RTK-GPS. Figure 1 shows the locations of the GCPs and Figure 4 shows one of the GCP targets.

For radiometric validation purposes we measured the reflectance of 14 reference reflectance plates (Figure 5) and 5 plant samples with a CropScan MSR87 (www.cropscan.com) (at 16:00pm) and a tec5 Handyspec spectrometer (www.tec5.com/en/products/custom-solutions/handyspec-field) (at 08:00am, 10:00am, 13:00pm).
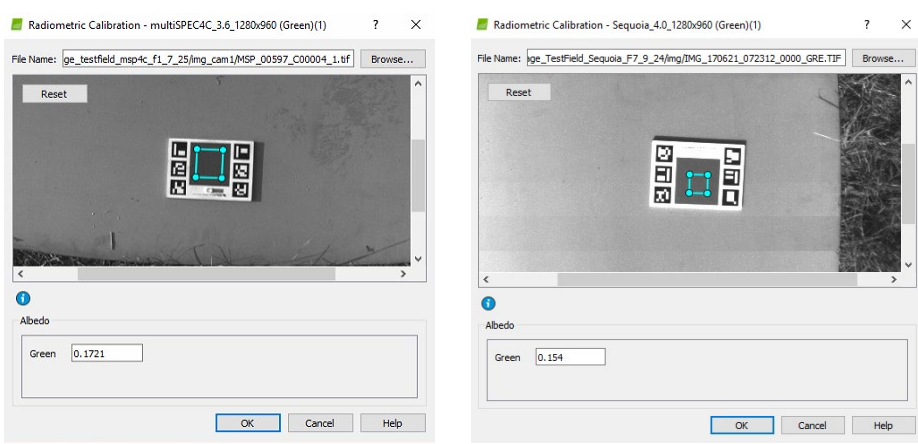

Figure 3. Airinov MultiSPEC 4C and Parrot Sequoia radiometric calibration targets
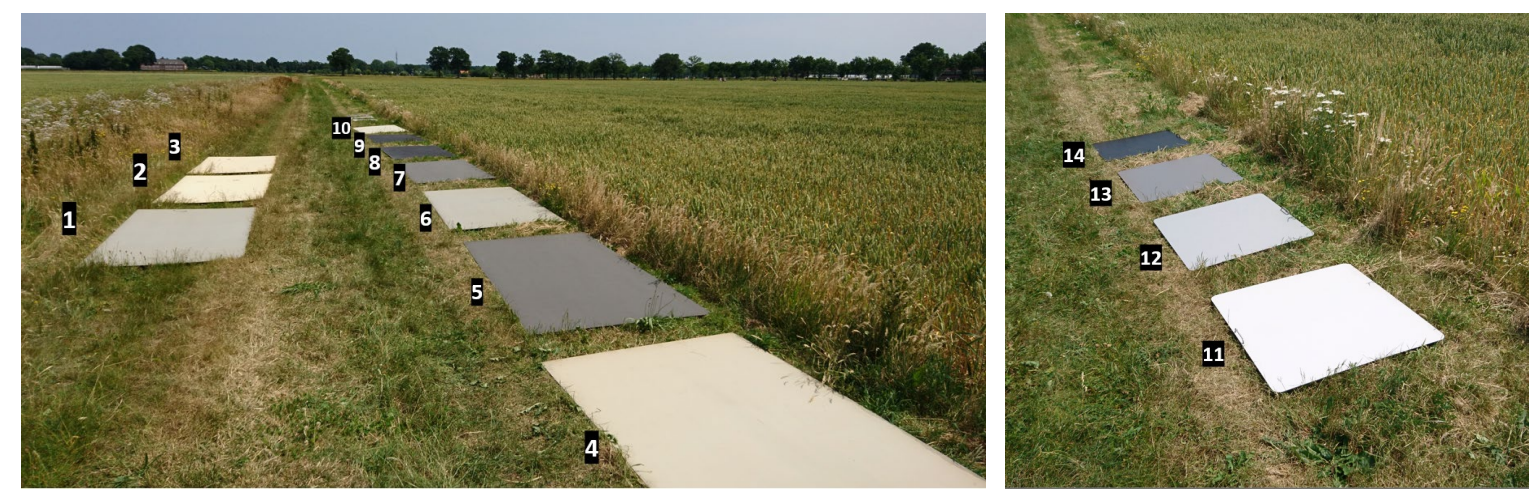

Figure 4. Reference reflectance panels

Figure 6 shows the reflectance target locations in the experimental fields, and Figure 7 shows the plants in the sampling locations. After flight \#3 the smaller calibrations plates (\#11 to 14) were moved approximately 6 meters to the west.

2.4 IMAGE PROCESSING \& DATA STRUCTURE:The raw images were post-processed with Pix4Dmapper Pro software package (version 3.1.18, Pix4D SA, Lausanne, Switzerland). Pix4Dmapper Pro automatically recognizes the camera model and applies the necessary parameters for the model reconstruction. The radiometric calibration targets included in the image folder are automatically recognized and albedo values per band are selected automatically based on the calibration target. For the geometric correction, the GCPs were added to each project and marked to the images manually.

Data are available per flight in a folder with a description name consisting of 'Year-MonthDay'_'Location'_Sensor'_'Flight ID'_'Start Time'. Within this folder, there are three folders considering the different levels of processing:

- Level 0. Raw image data, calibration plate images when applicable.

- Level 1. Raster data, radiometrically calibrated, not co-registered. Including the .pdf processing report when available.

- Level 2. Raster data, radiometrically calibrated, co-registered using GCPs. Including the .pdf processing report when available. 
Kallimani et al. 2020, Open Data Journal for Agricultural Research, vol. 6, p. 1-7

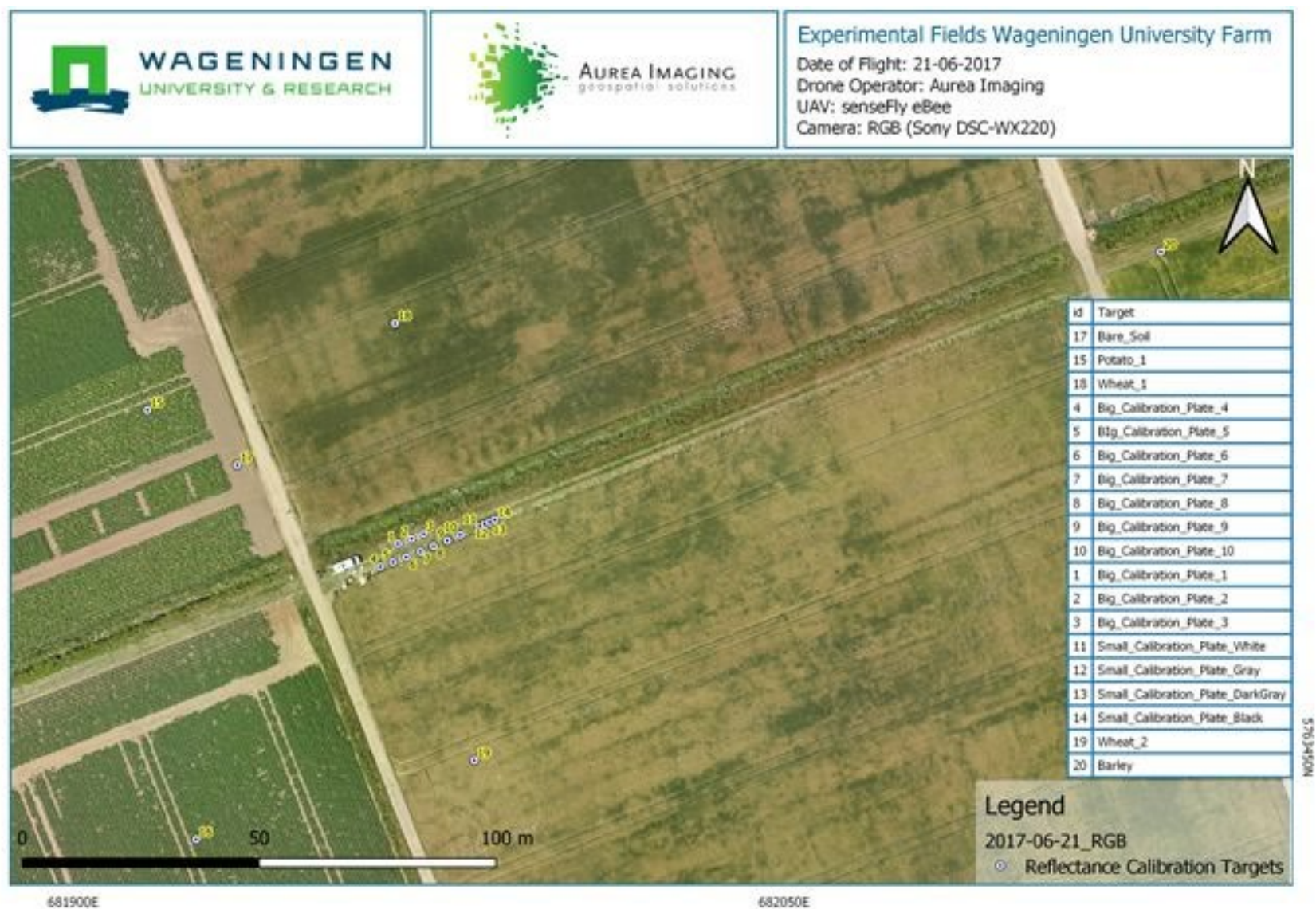

Figure 5. Locations of reflectance calibration targets \& description

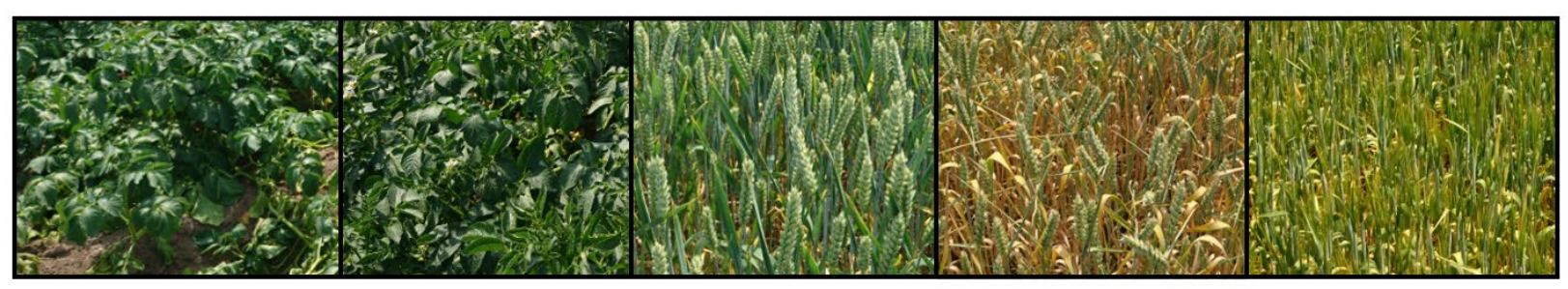

Figure 7. Potato, wheat and barley plants in sampling locations 15, 16, 18, 19, 20. 


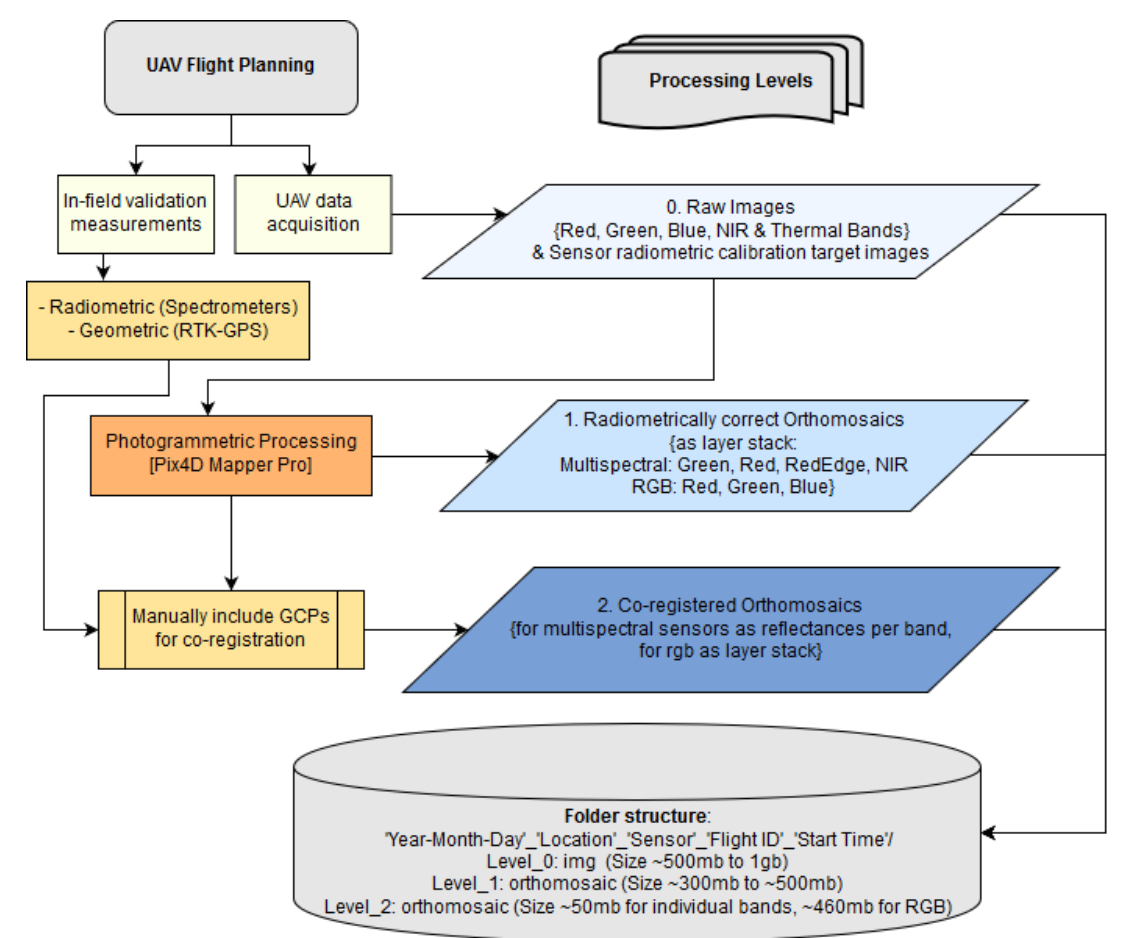

Figure 8. Data acquisition, processing workflow and output data

The Cropscan and tec5 Handyspec measurements are saved in Microsoft Excel files (.xlsx). The GCPs, experimental field boundaries, and reflectance targets locations are stored in shapefile format (shp).

ACKNOWLEDGEMENTS We thank Unifarm for providing access to the experimental fields and WUR for providing the validation equipment (spectrometers, reflectance calibration targets, RTK-GPS). We thank Johan Beekhuizen for reviewing the manuscript and his valuable feedback. Also, we thank the students and personnel joining us during the fieldwork.

\section{REFERENCES}

Aicardi, I., Nyapwere, N., Nex, F., Gerke, M., Lingua, A.M. and Koeva, M.N., 2016. "Co-Registration of Multitemporal Uav Image Datasets for Monitoring Applications: A New Approach.", Int. Arch. Photogramm. Remote Sens. Spatial Inf. Sci., XLI-B1, 757-763. doi: 10.5194/isprs-archives-XLIB1-757-2016

Assmann, J.J., Kerby, J.T., Cunliffe, A.M. and Myers-Smith, I.H., 2018. "Vegetation Monitoring Using Multispectral Sensors - Best Practices and Lessons Learned from High Latitudes." Journal of Unmanned Vehicle Systems, 2019, 7(1):54-75, 10.1139/juvs-2018-0018

Elarab, M., Ticlavilca, A.M., Alfonso F. Torres-Rua, Maslova, I. and McKee, M., 2015. "Estimating Chlorophyll with Thermal and Broadband Multispectral High Resolution Imagery from an Unmanned Aerial System Using Relevance Vector Machines for Precision Agriculture." International Journal of Applied Earth Observation and Geoinformation 43:32-42. doi: 10.1016/j.jag.2015.03.017

Gago, J., Douthe, C., Coopman, R.E., Gallego, P.P., Ribas-Carbo, M., Flexas, J., Escalona, J. and Medrano, H., 2015. "UAVs Challenge to Assess Water Stress for Sustainable Agriculture." Agricultural Water Management 153:9-19. doi: 10.1016/j.agwat.2015.01.020

Haghighattalab, A., González Pérez, L., Mondal, S., Singh, D., Schinstock, D., Rutkoski, J., OrtizMonasterio, I., Prakash Singh, R., Goodin, D. and Poland. J., 2016. "Application of Unmanned Aerial Systems for High Throughput Phenotyping of Large Wheat Breeding Nurseries." Plant Methods 12(1):35. doi: $10.1186 / \mathrm{s} 13007-016-0134-6$

Holman, F., Riche, A., Michalski, A., Castle, M., Wooster, M., and Hawkesford, M., 2016. "High Throughput Field Phenotyping of Wheat Plant Height and Growth Rate in Field Plot Trials Using UAV Based Remote Sensing." Remote Sensing 8(12):1031. doi: 10.3390/rs8121031 
Kelly, J., Kljun, N., Olsson, P.O., Mihai, L., Liljeblad, B., Weslien, P., Klemedtsson, L., Eklundh, L., 2019. "Challenges and Best Practices for Deriving Temperature Data from an Uncalibrated UAV Thermal Infrared Camera." Remote Sensing 11(5): 567. doi: 10.3390/rs11050567

Maes, W., Huete, A. and Steppe, K., 2017. "Optimizing the Processing of UAV-Based Thermal Imagery." Remote Sensing 9(5):476. doi: 10.3390/rs9050476

Peña, J.M., Torres-Sánchez, J., Serrano-Pérez, A., de Castro, A.I. and López-Granados, F., 2015. "Quantifying Efficacy and Limits of Unmanned Aerial Vehicle (UAV) Technology for Weed Seedling Detection as Affected by Sensor Resolution." Sensors (Switzerland) 15(3):5609-26. doi: $10.3390 / \mathrm{s} 150305609$

Potgieter, A.B., George-Jaeggli, B., Chapman, S.C., Laws, K., Suárez Cadavid, L.A., Wixted, J., Watson, J., Eldridge, M., Jordan, D.R. and Hammer, G.L., 2017. "Multi-Spectral Imaging from an Unmanned Aerial Vehicle Enables the Assessment of Seasonal Leaf Area Dynamics of Sorghum Breeding Lines." Frontiers in Plant Science 8(September):1-11. doi: 10.3389/fpls.2017.01532

Raeva, P.L., Šedina, J. and Dlesk, A., 2018. "Monitoring of Crop Fields Using Multispectral and Thermal Imagery from UAV." European Journal of Remote Sensing 00(00):1-10. doi: 10.1080/22797254.2018.1527661

Sankaran, S., Khot, L.R., Zúniga Espinoza, C., Jarolmasjed, S., Sathuvalli, V.R., Vandemark, G.J., Miklas, P.N., Carter, A.H., Pumphrey, M.O., Knowles, R.R.N. and Pavek, M.J., 2015. "LowAltitude, High-Resolution Aerial Imaging Systems for Row and Field Crop Phenotyping: A Review." European Journal of Agronomy 70:112-23. doi: 10.1016/i.eja.2015.07.004

Shi, Y., Thomasson, J.A., Murray, S.C., Pugh, N.A., Rooney, W.L., Shafian S., Neely, H.L., Rana, A., Bagavathiannan, M.V., Henrickson, J., Putman, E.B., Popescu, S., Burks, T., Cope, D. and Ibrahim, A., 2016. "Unmanned Aerial Vehicles for High-Throughput Phenotyping and Agronomic." c:1-26. doi: $10.5061 /$ dryad. $65 \mathrm{~m} 87$

Torres-Sánchez, J., López-Granados, F., De Castro, A.I. and Peña-Barragán, J.M., 2013. "Configuration and Specifications of an Unmanned Aerial Vehicle (UAV) for Early Site Specific Weed Management." PLoS ONE 8(3). doi: 10.1371/journal.pone.0058210

Zhang, C. and Kovacs, J.M., 2012. "The Application of Small Unmanned Aerial Systems for Precision Agriculture: A Review.” Precision Agriculture 13(6):693-712. doi: 10.1007/s11119-012-9274-5. 